\title{
A DFT Analysis of Electronic, Reactivity, and NLO responses of a Reactive Orange Dye: the Role of Hartree-fock Exchange Corrections
}

\section{Sávio Fonseca}

Universidade Federal do Sul e Sudeste do Para

\section{Lucas Santos}

Universidade Federal do Sul e Sudeste do Para

\section{Regina Pereira}

Universidade Federal do Sul e Sudeste do Para

\section{Lucas Modesto-Costa}

Universidade Federal do Sul e Sudeste do Para

\section{Antônio da Cunha}

Universidade Federal do Maranhão: Universidade Federal do Maranhao

\section{Marcelo Siqueira}

Universidade Federal do Amapá

\section{Francisco Carvalho}

Universidade Federal do Sul e Sudeste do Para

\section{Tarciso Andrade Filho}

Universidade Federal do Sul e Sudeste do Para

Rodrigo Gester ( $\square$ rodrigogester80@gmail.com )

Universidade Federal de Ciencias da Saude de Porto Alegredo Sul e Sudeste do Pará https://orcid.org/0000-0001-6110-424X

\section{Research Article}

Keywords: Azo dye, UV-Vis spectra, Nonlinear optics, Reactivity descriptors, Fukui functions, DFT/TD-DFT

Posted Date: October 18th, 2021

DOI: https://doi.org/10.21203/rs.3.rs-978314/v1

License: (c) (i) This work is licensed under a Creative Commons Attribution 4.0 International License.

Read Full License 
Version of Record: A version of this preprint was published at Journal of Molecular Modeling on March 7th, 2022. See the published version at https://doi.org/10.1007/s00894-022-05035-9. 


\title{
A DFT analysis of electronic, reactivity, and NLO responses of a reactive orange dye: The role of Hartree-Fock exchange corrections
}

\author{
Sávio Fonseca - Lucas Santos · Regina Pereira - Lucas Modesto-Costa · Antônio \\ R. da Cunha - Marcelo R.S. Siqueira - Francisco A. O. Carvalho * Tarciso \\ Andrade-Filho · Rodrigo Gester
}

Received: date / Accepted: date

\begin{abstract}
An experimental and theoretical study based on DFT/TD-DFT approximations is presented to understand the nature of electronic excitations, reactivity, and NLO properties of reactive orange 16 dye (RO16), an azo chromophore widely used in textile and pharmacological industries. The results show that the solvent has a considerable influence on the electronic properties of the material. According to experimental results, the absorption spectrum is noticed by four intense transitions, which have been identified as $\pi \rightarrow \pi^{*}$ states using TD-DFT calculations. However, the TD-DFT
\end{abstract}

Sávio Fonseca

Programa de Pós-Graduação em Química, Universidade Federal do Sul e Sudeste do Pará, Marabá-PA, 68507-590, Brazil.

Lucas Santos

Programa de Pós-Graduação em Química, Universidade Federal do Sul e Sudeste do Pará, Marabá-PA, 68507-590, Brazil.

Regina Pereira

Programa de Pós-Graduação em Química, Universidade Federal do Sul e Sudeste do Pará, Marabá-PA, 68507-590, Brazil.

Lucas Modesto-Costa

Programa de Pós-Graduação em Química, Universidade Federal do Sul e Sudeste do Pará, Marabá-PA, 68507-590, Brazil.

Antônio R. da Cunha

Universidade Federal do Maranhão, UFMA, Campus Balsas, CEP 65800-000, Maranhão, Brazil.

Marcelo R.S. Siqueira

Curso de Física, Universidade Federal do Amapá, 68903-329, MacapáAP, Brazil.

Francisco A. O. Carvalho

Faculdade de Química, Universidade Federal do Sul e Sudeste do Pará, Marabá-PA, 68507-590, Brazil.

Tarciso Andrade-Filho

Faculdade de Física, Universidade Federal do Sul e Sudeste do Pará, Marabá-PA, 68507-590, Brazil.

Rodrigo Gester

Faculdade de Física, Universidade Federal do Sul e Sudeste do Pará, Marabá-PA, 68507-590, Brazil. E-mail: gester@unifesspa.edu.br results reveal a weak $n \rightarrow \pi^{*}$ in the low-lying spectral region. Continuum models of solvation indicate that these states suffer bathochromic and hypsochromic shifts, respectively. However, the expected blue shift for the absorption $n \rightarrow \pi^{*}$ is only described using long-range or dispersion-corrected DFT methods. RO16 is classified as a strong electrophilic system $(\omega>1.5 \mathrm{eV})$. From vacuum to solvent, the environment is active and changes the nucleophilic status from strong to moderate nucleophile $(2.0 \leq N \leq 3.0 \mathrm{eV})$. The results also suggest that all electrical constants are strongly dependent on long-rang and Hartree-Fock exchange contributions, and the absence of these interactions gives results far from reality. In particular, the results for the NLO response show that the chromophore presents a potential application in this field, with a low refractive index, and firsthyperpolarizability ca. 214 times bigger than the value usually reported for urea $\left(\beta=0.34 \times 10^{-30} \mathrm{esu}\right)$, which is a standard NLO material. Concerning the solvent effects, the results indicate that $\beta_{\text {total }}$ increases ca. $180 \%$ regarding the gas-phase value. The results suggest RO16 is a potential compound in NLO applications.

Keywords Azo dye - UV-Vis spectra $\cdot$ Nonlinear optics Reactivity descriptors · Fukui functions - DFT/TD-DFT

\section{Introduction}

Since it was discovered in the 60's [1], nonlinear optics (NLO) has figured as a prominent field in the science of materials. Organic and inorganic chromophores with higher NLO response can be used to built a variety of devices, such as field-effect transistors [2,3], light-emitting diodes [4,5], solar cells $[6-8]$, and sensors $[9,10]$ that can improve logical circuits. The biggest advantage of such devices is their data transfer speed, once part of the information is performed at the light-speed limit. Consequently, NLO devices are quite 
superior to traditional electronic circuits. These features justify the interest of areas such as telecommunications engineering in obtaining materials with large ONL activity [11].

Besides the NLO effects, the electronic excitations of many chromophores present relevant applications. For instance, the Stokes shift is the difference between the positions of an electronic state in the emission and absorption spectra. Thus, chromophores with a higher Stokes shift are used as biological markers, and probes that verbalize the diagnostics of human diseases throughout bioimaging $[12,13]$. Although $\pi \rightarrow \pi^{*}$ occurs with higher intensity, the Stokes shift of weak $n \rightarrow \pi^{*}$ states is relevant once these excitations usually happen with lower energies [14-16], pertinent feature for devices like solar cells, for instance.

Thus, due to the features discussed above, the science of materials has invested many efforts into developing and discover new compounds with enhanced NLO behavior. In this race, organic chromophores have shown superior performance. First, they present a higher limit of rupture when exposed to high-power lasers. Moreover, organic molecules allow greater miniaturization capacity in comparison to inorganic materials. Finally, organic compounds can be conveniently modified by chemical synthesis, improving their NLO feature. Between such dyes, one can cite chalcones $[17,18]$, and squaraines $[19,20]$.

However, as any experimental attack is expensive and demands much time, it is imperative to model the molecular NLO behavior using molecular modeling and quantum mechanics techniques. Within this scenery, Density Function Theory (DFT) [21,22] has gained special emphasis. In the DFT days, the old functionals faced problems like the description of van der Waals forces, long-range corrections, and including the Hartree-Fock exchange term. Nowadays, these problems have been solved, and DFT methods have been used to describe a series of molecular properties like reactivity, electronic excitations, and the NLO behavior of diverse chromophores [23-26]. Moreover, DFT and other quantum chemical approximations have been combined to liquid and solid-state simulations, giving information concerning how the environment affects the optical properties of a chromophore [16,27,28].

In particular, azo dyes are an interesting case. Azo compounds are $\pi$-systems made up of aromatic rings connected by azo-bridges $(-\mathrm{N}=\mathrm{N}-)$ which behave like an entire pushpull system, favoring the electronic polarization. Because of their reactivity, these chromophores are often applied as antiviral and antifungal drugs [29-31]. The reactive orange (RO16) present in Fig. 1 is one of such chromophores which has attracted attention due to its use in the textile industry. For this reason, there is great concern about how to remove this chromophore from water effluents [32-34]. However, almost nothing is known about its electronic properties.

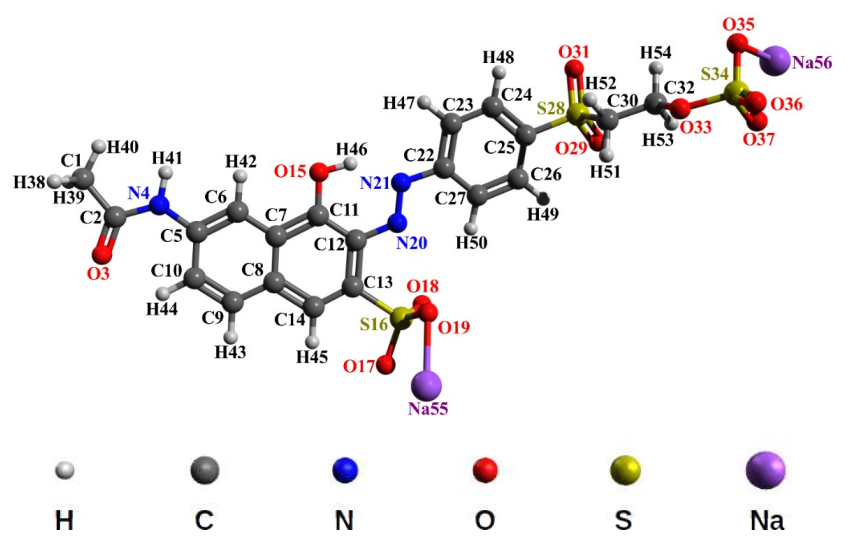

Fig. 1 The trans structure of reactive orange 16, and the respective atomic labels.

For the first time, this work presents a discussion of the optical properties of an azo dye known as reactive orange 16 (RO16) showed in Fig. 1. Throughout experimental, DFT, and Time-Dependent DFT calculations, it characterizes the electronic absorption and emission spectra. Quantum mechanical results account for solvent effects, long-range (LC) interactions, and Hartree-Fock exchange (HFE) contributions. The experimental report reveals four strong excitations, which have been characterized as $\pi \rightarrow \pi^{*}$ absorptions. However, the TD-DFT analysis reports that the lowest absorption energy belongs to a weak $n \rightarrow \pi^{*}$ state. However, this state is not experimentally observed once it is covered by an intense $\pi \rightarrow \pi^{*}$ one.

Concerning the NLO behavior, RO16 presents great potentialities. For instance, the first hyperpolarizability is ca. 214 times bigger than that value reported for urea $(\beta=0.34 \times$ $\left.10^{-30} \mathrm{esu}\right)[35,36]$, which is a standard NLO material. These results suggest that RO16 is a promise as NLO material. Finally, the satisfactory description of the RO16 photophysics and NLO behavior depends on the inclusion of LC and HFE corrections.

\section{Methodology}

\subsection{Theoretical details}

Although azo dyes can be stable either in trans as cis geometries, trans-isomers are those with the highest NLO response [27], the focus of this work. The molecular geometries of the reactive orange 16 at the ground and the first excited states were optimized within the framework of density functional theory using the CAM-B3LYP approximation [37] and the standard 6-311++G $(d, p)$ basis set [38-42]. Then, a posterior analysis of the infrared spectra showed that all vibrational frequencies are positive, confirming that the molecular geometry is on a local minimum of energy. 
Concerning the description of the electronic absorption and emission spectra, the results take advantage of the 6$311++\mathrm{G}(d, p)$ basis set coupled to the Coulomb attenuated version of the B3LYP method (CAM-B3LYP) [37]. Concerning the description of the NLO and reactive properties, besides the standard B3LYP [43,44] and CAM-B3LYP [37] approximations, the performances of the family of Minnesota exchange-correlation functionals (M06-L [45], M06 [46], M06-2X [47]), and M06-HF [48] have been considered. In particular, M05-2X and M06-2X functionals have shown superior performances in describing the global reactivity [49] and NLO [50] parameters, respectively. Besides DFT, the semi-empirical PM6 [51] method is considered for reactivity and NLO calculations.

The NLO effects arise when the light interacts with the matter. In such a case, one can expand the energy of the system in Taylor series:

$E(F)=E(0)-\mu_{i} F_{i}-\frac{1}{2} \alpha_{i j} F_{i} F_{j}-\frac{1}{6} \beta_{i j k} F_{i} F_{j} F_{k}+\ldots$

In this equation, $\mu$ and $\alpha$ are the molecular dipole moment and dipolar polarizability. The first is a vector given by

$\mu=\sqrt{\mu_{x}^{2}+\mu_{y}^{2}+\mu_{z}^{2}}$.

On the other hand, the dipolar polarizability is a tensor which the diagonal elements can be combined to given the isotropic $(\langle\alpha\rangle)$ and anisotropic $(\Delta \alpha)$ contributions

$\langle\alpha\rangle=\frac{1}{3}\left(\alpha_{x x}+\alpha_{y y}+\alpha_{z z}\right)$

and

$\Delta \alpha=\sqrt{\left(\alpha_{x x}-\alpha_{y y}\right)^{2}+\left(\alpha_{x x}-\alpha_{z z}\right)^{2}+\left(\alpha_{y y}-\alpha_{z z}\right)^{2}}$.

The theoretical polarizability can be used to infer the refractive index $(n)$ using the Lorentz-Lorenz equation $[52,53]$

$\frac{n^{2}-1}{n^{2}+2}=\frac{4 \pi\langle\alpha\rangle}{3 V_{\mathrm{mol}}}$,

where $V_{\text {mol }}$ is the molecular volume.

The static version first hyperpolarizability is a tensor given for a cubic matrix $(3 \times 3 \times 3)$ with 27 elements. However, appropriate symmetry rules $\left(\beta_{i j j}=\beta_{j i j}=\beta_{j j i}\right)$ [54] reduces this number to 10 distinct elements which are combined to give the static $\beta_{\text {total }}$

$\beta_{\text {total }}=\sqrt{\beta_{x}^{2}+\beta_{y}^{2}+\beta_{z}^{2}}$,

where

$\beta_{x}=\beta_{x x x}+\beta_{x y y}+\beta_{x z z}$

$\beta_{y}=\beta_{y y y}+\beta_{y x x}+\beta_{y z z}$

$\beta_{z}=\beta_{z z z}+\beta_{z x x}+\beta_{z y y}$
Regarding the reactivity of the chromophore, one can deal with global and local parameters. The global reactivity is mainly discussed in terms of the chemical potential $(\mu)$, ionization energy (IP), electron affinity (EA), hardness $(\eta)$, electrophilicity $(\omega)$, and nucleophilicity. The first three parameters are calculated as [55]

$\mu=\left(E_{\mathrm{HOMO}}+E_{\mathrm{LUMO}}\right) / 2=-\chi$

$\mathrm{IP}=-E_{\mathrm{HOMO}}$

$\mathrm{EA}=-E_{\mathrm{LUMO}}$

$\eta=\left(E_{\mathrm{LUMO}}-E_{\mathrm{HOMO}}\right) / 2$,

and

$\omega=\frac{\mu^{2}}{2 \eta}$.

For the nucleophilicity $(N)$ index, we adopt an empirical scale developed for closed-shell systems based on the HOMO energies, defined as $[56,57]$

$N=E_{\text {Nucleophile }}-E_{\mathrm{TCNE}}$.

In the equation above, the calculations are performed on the tetracyanothylene (TCNE) molecule also obtained within the CAM-B3LYP/6-311++G $(d, p)$ formalism.

The local reactivity parameters if often discussed using the Fukui functions, which describe the selectivity or reactivity of an atomic site or a region in a chemical chromophore. This parameters are given by [58]

$F_{k}^{+}=q_{k}(N+1)-q_{k}(N)$, for nucleophilic attack

and

$F_{k}^{-}=q_{k}(N)-q_{k}(N-1)$, for electrophilic attack,

where $q_{k}(N), q_{k}(N+1)$, and $q_{k}(N-1)$ are the electronic populations on the $k$ th atomic site for $N, N+1, N-1$ electron systems, respectively.

Other two relevant parameters are the relative nucleophilic $\left(f_{\text {nu }}=F_{k}^{+} / F_{k}^{-}\right)$and electrophilic $\left(f_{\mathrm{el}}=F_{k}^{-} / F_{k}^{+}\right)$indexes. When $f_{\mathrm{nu}}>f_{\mathrm{el}}$, the atomic site is facing to nucleophilic attack. In another way, $f_{\mathrm{el}}>f_{\text {nu }}$ designates an electrophilic attack in a nucleophilic site [58-62]. Finally, all electronic calculations were carried out in Gaussian 09 package [63].

\subsection{Experimental details}

Reactive orange dye 16 (RO-16), ID: 24858342, with a molecular weight of $617.54 \mathrm{~g} / \mathrm{mol}$ was purchased from SigmaAldrich Company, Saint Louis, USA, with the content of $70 \%$. Initially, a solution of $50 \mathrm{~mL}$ of RO-16 was prepared at a concentration of $10 \mathrm{mg} / \mathrm{L}$. Then, the measurement was performed in a brand spectrophotometer (Digital Double Beam - GTA - 101) in a quartz cuvette with an optical path of $1 \mathrm{~cm}$ and $1 \mathrm{ml}$. 


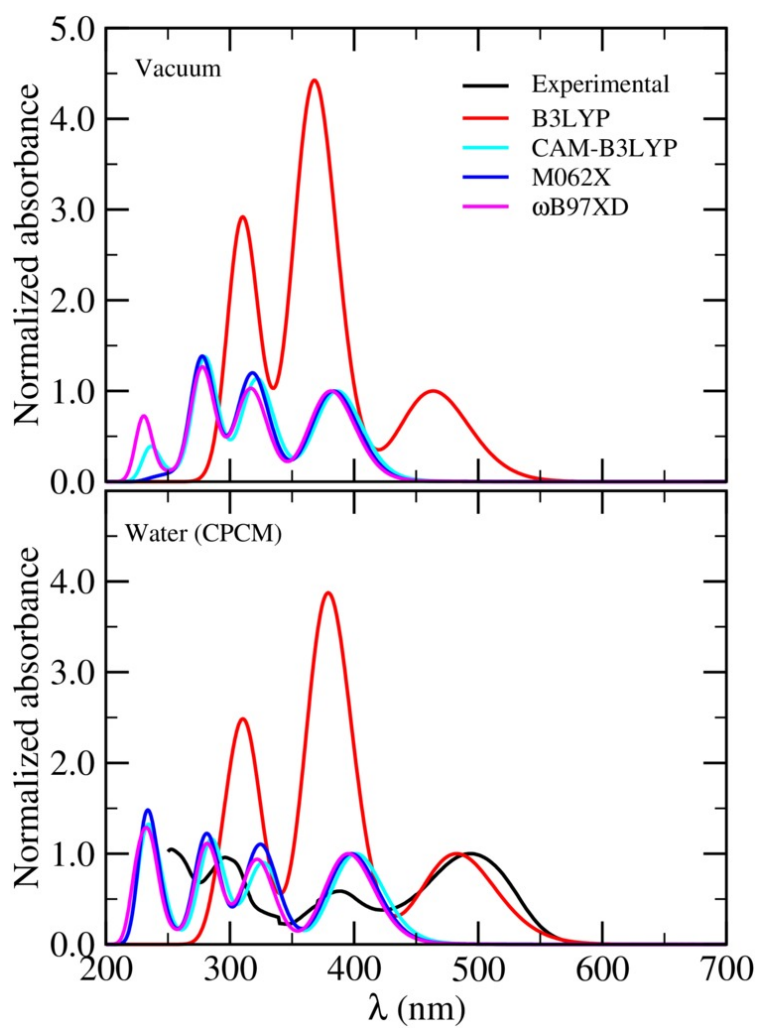

Fig. 2 Absorption spectra of reactive orange 16 calculated in vacuum and water using different methods (B3LYP, CAM-B3LYP, M06-2X, and $\mathrm{wB}^{2}$ 7XD) and the same basis set $6-311++\mathrm{G}(d, p)$. In water, the spectra were obtained using the solvent described by C-PCM with the same level of QM calculation.

\section{Results and discussions}

\subsection{Electronic excitations}

The experimental absorption spectrum of the RO16 in water is shown in Fig. 2. According to this spectrum, four absorption bands can be observed: two in the visible region, with their maxima wavelengths $\left(\lambda_{\max }\right)$, centered at 493 and 388 $\mathrm{nm}$, and two in the ultraviolet region with $\lambda_{\max }$ at 296 and $253 \mathrm{~nm}$. These two bands in the visible region were assigned as $n \rightarrow \pi^{*}$, and the two bands in the UV region as $\pi \rightarrow \pi^{*}$ [64]. The obtained spectrum for RO16 agrees very well with previous results reported in the literature [64-66]. The bands at 493 and $388 \mathrm{~nm}$ are attributed to the chromophore and azo group [66]. In comparison, the bands at 296 and $253 \mathrm{~nm}$ are related to the structure of gamma acetylated and aromatic rings [66], respectively.

Table 1 shows the maximum wavelengths $\left(\lambda_{\max }\right)$ and oscillator strength of the five lowest transitions of orange 16 calculated in vacuum and water using different methods. As can be seen, in the gas phase, B3LYP provides two transitions in the visible region at 477.7 and $462.5 \mathrm{~nm}$ and three transitions in the UV region at $367.8,310.5$, and $295.5 \mathrm{~nm}$, the first and last transitions being extremely weak. Due to its low intensity, this first transition is hardly observed in the experiment, although it was also predicted using other DFT functionals (CAM-B3LYP, M06-2X, and $\omega$ B97XD) at $440.2,479.5$, and $445.7 \mathrm{~nm}$. This first transition arises from HOMO- $\rightarrow$ LUMO and is assigned as an $n \rightarrow \pi^{*}$ for all DFT functionals used in this work. For the other four transitions, B3LYP provides values for $\lambda_{\max }$ about 80, 50, 30, and 60 $\mathrm{nm}$ too high for the four transitions compared to other methods (CAM-B3LYP, M06-2X, and $\omega$ B97XD), which provide very similar results. Moreover, B3LYP gives the four transitions with very different oscillator strength values $(0.17$, $0.78,0.49$, and 0.03 ). While other methods provide similar values of $f$ for the four transitions, presenting the 4th transition as the weakest. These methods, which include longrange or dispersion corrections, predict the four absorption bands blue-shifted concerning B3LYP results. To the best of our knowledge, the experimental results for the absorption spectra of RO16 are unavailable in the scientific literature.

Normally, from gas to solvent, $n \rightarrow \pi^{*}$ states suffer a hypsochromic effect $[16,67]$, and for RO16, this behavior is not different. Comparing the gas phase and in water B3LYP results, it was observed that the weak $n \rightarrow \pi^{*}$ transition exhibits a blue shift of $4 \mathrm{~nm}$, and was found inverted concerning the position of second transition. This small blue shift was also observed with the other methods (CAM-B3LYP, M06-2X, and $\omega \mathrm{B} 97 \mathrm{XD})$, but the $n \rightarrow \pi^{*}$ transition was not inverted. Normally, from gas to solvent, $n \rightarrow \pi^{*}$ states suffer a hypsochromic effect $[16,67]$, and for RO16, this behavior is no different. Comparing the gas phase and in water B3LYP results, it was observed that the weak $n \rightarrow \pi^{*}$ transition exhibits a blue shift of $4 \mathrm{~nm}$ and was found inverted concerning the position of the second transition. This slight blue shift also was observed with the other methods (CAMB3LYP, M06-2X, and $\omega$ B97XD), but the $n \rightarrow \pi^{*}$ transition was not inverted. This result indicates that long-range interactions are essential if one desires to describe $n \rightarrow \pi^{*}$ states. In contrast, for the other four transitions, we observe a redshift of the entire spectrum. With the B3LYP, this redshift was $21,12,3$, and $1 \mathrm{~nm}$ from the gas phase to water, and for the other methods (CAM-B3LYP, M06-2X, and $\omega$ B97XD), the average values were $14,6,4$, and $4 \mathrm{~nm}$, respectively. It is also interesting to note that solvent increases oscillator strength values for these four transitions compared to the gas phase. The 5th transition presents the most significant increase in this property.

Comparing the experimental results, we observe that the best agreement with observed two first $\pi \rightarrow \pi^{*}$ transitions is obtained with B3LYP, giving wavelengths differences of 10 and $8 \mathrm{~nm}$ for the 2nd and 3rd transitions. For the other $\pi \rightarrow \pi^{*}$ transitions (4th and 5 th), this best agreement was obtained with CAM-B3LYP, with these values of 13 and 12 $\mathrm{nm}$, which also agrees with M06-2X and $\omega \mathrm{B} 97 \mathrm{XD}$ results. Thus, our results show that the use of a non-long-range DFT 
Table 1 Maximum wavelengths $(\lambda / \mathrm{nm})$, oscillator strength $(f)$ of the three lowest transitions of reactive orange 16 calculated in vacuum and water using different methods (B3LYP, CAM-B3LYP, M06-2X, and $\omega$ B97XD) and the same 6-311++G $(d, p)$ basis set:

\begin{tabular}{|c|c|c|c|c|c|c|c|c|c|}
\hline \multirow[b]{2}{*}{ Vacuum } & \multicolumn{2}{|c|}{ B3LYP } & \multicolumn{2}{|c|}{ CAM-B3LYP } & \multicolumn{2}{|c|}{ M06-2X } & \multicolumn{2}{|c|}{$\omega \mathrm{B} 97 \mathrm{XD}$} & \multirow{2}{*}{$\begin{array}{l}\text { Exp. } \\
\lambda_{\max }\end{array}$} \\
\hline & $\lambda_{\max }$ & $f$ & $\lambda_{\max }$ & $f$ & $\lambda_{\max }$ & $f$ & $\lambda_{\max }$ & $f$ & \\
\hline 1 st $\left(n \rightarrow \pi^{*}\right)$ & 477.69 & 0.01 & 440.16 & 0.00 & 479.48 & 0.00 & 445.73 & 0.00 & - \\
\hline $2 \mathrm{nd}\left(\pi \rightarrow \pi^{*}\right)$ & 462.46 & 0.17 & 386.15 & 0.48 & 383.12 & 0.48 & 381.06 & 0.51 & - \\
\hline $\operatorname{3rd}\left(\pi \rightarrow \pi^{*}\right)$ & 367.76 & 0.78 & 321.54 & 0.54 & 317.81 & 0.57 & 316.51 & 0.52 & - \\
\hline $4 \operatorname{th}\left(\pi \rightarrow \pi^{*}\right)$ & 310.45 & 0.49 & 279.55 & 0.65 & 277.43 & 0.60 & 277.46 & 0.64 & - \\
\hline 5 th $\left(\pi \rightarrow \pi^{*}\right)$ & 303.73 & 0.02 & 264.38 & 0.02 & 276.84 & 0.06 & 261.89 & 0.02 & - \\
\hline \multicolumn{10}{|l|}{ Water } \\
\hline 1 st $\left(n \rightarrow \pi^{*}\right)$ & 473.41 & 0.00 & 438.00 & 0.01 & 476.59 & 0.00 & 443.72 & 0.01 & - \\
\hline $2 \mathrm{nd}\left(\pi \rightarrow \pi^{*}\right)$ & 483.39 & 0.23 & 400.63 & 0.58 & 397.33 & 0.58 & 394.92 & 0.62 & 493 \\
\hline $3 \operatorname{rd}\left(\pi \rightarrow \pi^{*}\right)$ & 379.85 & 0.89 & 327.53 & 0.60 & 324.18 & 0.64 & 321.54 & 0.58 & 388 \\
\hline 4 th $\left(\pi \rightarrow \pi^{*}\right)$ & 313.53 & 0.48 & 283.39 & 0.70 & 281.09 & 0.71 & 281.37 & 0.68 & 296 \\
\hline $5 \operatorname{th}\left(\pi \rightarrow \pi^{*}\right)$ & 296.53 & 0.19 & 240.81 & 0.36 & 239.73 & 0.32 & 235.85 & 0.60 & 253 \\
\hline
\end{tabular}

functional (B3LYP) provides an appropriate description of the 2 nd and 3rd transitions. The corrected functionals provide a satisfactory description of the 4 th and 5th transitions of RO16 in water.

\subsection{Dipole moment and dipolar polarizability}

Table 2 shows the results obtained for the molecular dipole moment $(\mu)$, dipole polarizability $(\alpha)$, molecular volume $\left(V_{\text {mol }}\right)$, and the refractive index $(n)$ for the RO16 molecule in a water solvent, using different approaches of quantum mechanics and the C-PCM, which is an adequate continuum model to discuss NLO parameters. This discussion considers three effects: the influence of long-range interactions, the role of Hartree-Fock exchange, and the effects of the solvent.

The long-range corrections (LC) act polarizing the reference molecule, increasing its dipole moment. For instance, the B3LYP results predict a value of $2.59 \mathrm{D}$ for $\mu$. However, after including LC corrections using the CAM-B3LYP functional, the molecular dipole increases to $2.65 \mathrm{D}$. The inclusion of HF exchange causes similar effects. For instance, the Minnesota family of density functionals (M06-L, M06, M06-2X, and M06-HF) accounts for zero, 24\%, 54\%, and $100 \%$ of HF exchange. They predict the dipole moment as $2.53,2.57,2.67$, and 2.87 D, respectively. Such effects better realized in Fig. 3a.

Concerning the solvent effects, Table 2 also allows for comparing the values obtained for $\mu, \alpha$, and $n$. In the particular case of the dipole moment in both gas $(2.19 \mathrm{D})$ and solvent $(2.67 \mathrm{D})$ using the M06-2X method. These values indicate a polarization effect of ca. $17 \%$, concerning the gasphase value, and agree with other data that predict polarization effects which can achieve $30 \%$ or even $40 \%$ [28,68-70].

Contrasting the dipole moment, the dipolar polarizability $(\alpha)$ also presents an opposite correlation concerning the inclusion of long-range corrections and HF exchange terms

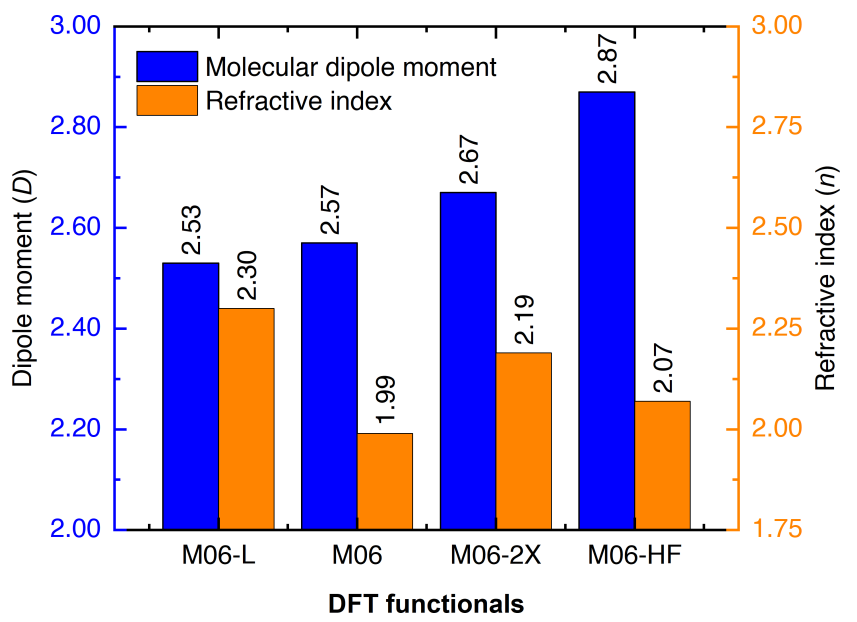

(a)

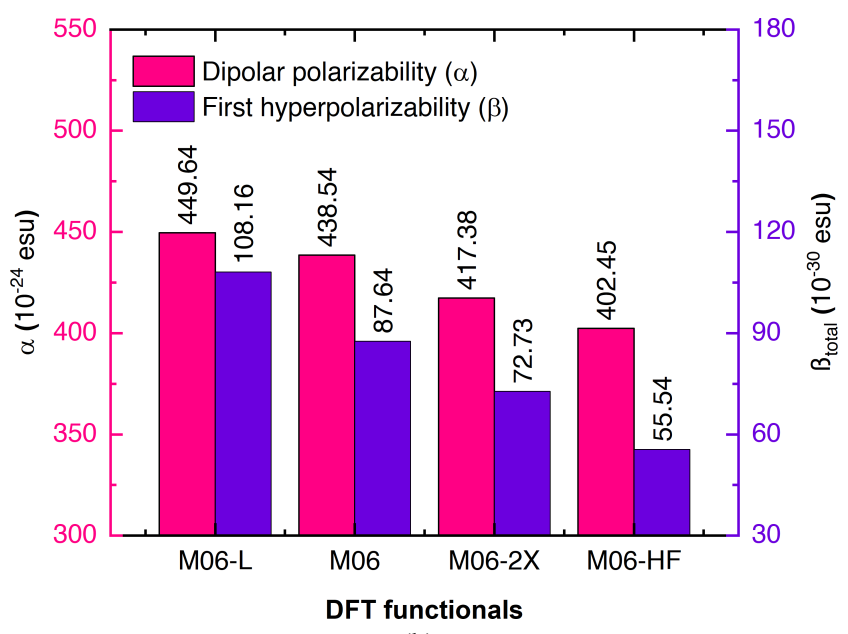

(b)

Fig. 3 The evolution of the refractive index, dipole moment, dipole polarizability, and the first hyperpolarizability $\left(n, \mu,\langle\alpha\rangle\right.$, and $\left.\beta_{\text {total }}\right)$ as function of the Hartree-Fock exchange. 
Table 2 The molecular dipole moment $(\mu / \mathrm{D})$, the components of the dipolar polarizability $\left(\alpha / 10^{-24}\right.$ esu), molecular volume $\left(V_{\text {mol }}\right)$, and the refractive index $(n)$ calculated for different degrees of quantum chemistry and the $6-311++\mathrm{G}(d, p)$ basis set:

\begin{tabular}{|c|c|c|c|c|c|c|c|c|}
\hline QM & $\mu$ & $\alpha_{x x}$ & $\alpha_{y y}$ & $\alpha_{z z}$ & $\langle\alpha\rangle$ & $\Delta \alpha$ & $V_{\text {mol }}$ & $n$ \\
\hline B3LYP & 2.59 & 137.59 & 76.81 & 49.08 & 87.83 & 110.89 & 4024.70 & 2.41 \\
\hline CAM-B3LYP & 2.65 & 123.82 & 74.01 & 47.95 & 81.92 & 94.43 & 4360.09 & 2.10 \\
\hline M06-L & 2.53 & 143.13 & 76.54 & 47.62 & 89.10 & 119.97 & 4276.24 & 2.30 \\
\hline M06 & 2.57 & 135.38 & 75.89 & 48.60 & 86.63 & 108.69 & 4947.02 & 1.99 \\
\hline M06-2X & 2.67 & 123.17 & 73.47 & 47.26 & 81.30 & 94.45 & 4108.54 & 2.19 \\
\hline M06-2X (Gas) & 2.19 & 98.95 & 52.48 & 34.11 & 61.85 & 81.87 & 4018.54 & 1.82 \\
\hline M06-HF & 2.87 & 113.71 & 71.83 & 47.53 & 77.69 & 82.01 & 4192.39 & 2.07 \\
\hline PM6 & 3.10 & 106.51 & 61.66 & 23.07 & 63.75 & 102.29 & 4863.17 & 1.66 \\
\hline
\end{tabular}

in DFT methods. For instance, from B3LYP to CAM-B3LYP, the isotropic $\langle\alpha\rangle$ varies from $87.83 \times 10^{-24}$ to $81.92 \times 10^{-24}$ esu. Moreover, considering the systematic inclusion of HF exchange, the Minnesota functionals predict that decreases from $89.10 \times 10^{-24}$ to $77.69 \times 10^{-24}$ esu, which is a variation of $13 \%$. Figure $3 \mathrm{~b}$ points out such behavior.

Similar to other azo dyes [24,27], the trans isomer of RO16 presents major anisotropic contributions $(\Delta \alpha)$. For instance, the M06-2X results show values of $81.30 \times 10^{-24}$ and $94.45 \times 10^{-24}$ esu respectively for $\langle\alpha\rangle$ and $\Delta \alpha$, and all other methods confirm this tendency.

By combining $\langle\alpha\rangle$, and the molecular volume $\left(V_{\mathrm{mol}}\right)$, one can obtain the refractive index $(n)$ throughout the LorentzLorenz equation [52,53]. Analyzing the results showed in Table 2 one can observe that the B3LYP prediction $(n=$ 2.41 ) is not realistic once this functional overestimates $n$ concerning the other methodologies. However, including longrange corrections using the CAM-B3LYP model, one obtains $n=2.10$. On the other side, the Minnesota family of functionals shows that the refractive index decreases regarding the inclusion of the HF exchange term, achieving a value of 2.07 using the M06-HF method and the C-PCM model.

As the refractive index $(n=c / v)$ is the ratio between the light speed in the vacuum and a particular environment, lower $n$ values designate great capacity of data transference. The results for the RO16 molecule are stimulating. For instance, refractive indexes of 1.76 and 1.89 respectively for the cis and trans isomers of an azo-azomethine dye [27]. Valverde [71], and Hodgkinson [72] have estimated refractive indexes of 1.71 and 2 for crystallized chalcones and pristine oxide, respectively.

Concerning the solvent effect (see Table 2), from vacuum to an aqueous environment, the solute polarization due to solvent acts improving all quantities. For instance, the isotropic contributions for the polarizability increases from $61.85 \times 10^{-24}$ to $81.30 \times 10^{-24} \mathrm{esu}$, which is a variation of ca. $31 \%$ concerning the gas-phase value. Both $\Delta \alpha$ and $n$ show similar trend.
Table 3 The frontier orbital energies $\left(\varepsilon_{\mathrm{H}, \mathrm{L}} / \mathrm{eV}\right)$, energy-gap $\left(E_{\mathrm{gap}} / \mathrm{eV}\right)$, the components of the first hyperpolarizability $\left(\beta / 10^{-30}\right.$ esu) calculated for different degrees of quantum chemistry and the 6$311++\mathrm{G}(d, p)$ basis set:

\begin{tabular}{llllll}
\hline QM & $E_{\text {gap }}$ & $\beta_{x}$ & $\beta_{y}$ & $\beta_{z}$ & $\beta_{\text {total }}$ \\
\hline B3LYP & 3.03 & -92.63 & 4.00 & -15.12 & 93.94 \\
CAM-B3LYP & 5.38 & -65.98 & 5.72 & -10.94 & 67.13 \\
M06-L & 1.99 & -106.78 & -1.00 & -17.18 & 108.16 \\
M06 & 3.42 & -86.54 & 3.20 & -13.49 & 87.64 \\
M06-2X & 5.02 & -71.58 & 5.28 & -11.71 & 72.73 \\
M06-2X (Gas) & 5.10 & 27.50 & 1.86 & 3.37 & 27.77 \\
M06-HF & 7.71 & -54.14 & 8.43 & -9.07 & 55.54 \\
PM6 & 6.98 & -66.90 & 14.10 & -10.58 & 69.18 \\
\hline
\end{tabular}

\subsection{Fist-hyperpolarizability}

Table 3 shows the values obtained for the first hyperpolarizability $\left(\beta_{\text {total }}\right)$ under static conditions. Again, these results consider three points: the effects of long-range corrections, including Hartree-Fock exchange, and the solvent contributions. Concerning the role of long-range corrections, the CAM-B3LYP results predict a value of $66.88 \times 10^{-30}$ esu for $\beta_{\text {total }}$, which is an improvement of $29 \%$ regarding the value of $93.87 \times 10^{-30}$ esu predicted using B3LYP.

The systematic inclusion of HF exchange also causes a decrease in the first hyperpolarizability. For instance, the M06-L functional does not consider any percent of HF contributions and predicts $108.21 \times 10^{-30}$ esu for $\beta_{\text {total }}$. However, the other Minnesota functionals, M06, and M06-2X functionals, which propose respectively zero, $27 \%$, and $54 \%$ of HF exchange, predict $87.64 \times 10^{-30}, 72.73 \times 10^{-30}$. and $55.54 \times 10^{-30}$ esu. As one can observe, from M06-L to M06HF methods, the HFE corrections improves in ca. $49 \%$ the description of $\beta_{\text {total }}$. This behavior is better observed in Fig. $3 b$.

As most organic NLO chromophores are large molecules that can demand great computational power, we tested the performances of the PM6 and PM7 semi-empirical methods. From Table 3, one can observe that both approximations reproduce all aspects assigned by DFT methods. For instance, they are assertive when predicting that the most contribution for the first hyperpolarizability comes from $\beta_{x}$. However, the PM6 estimate $\left(\beta_{\text {total }}=68.06 \times 10^{-30} \mathrm{esu}\right)$ is the best result, 

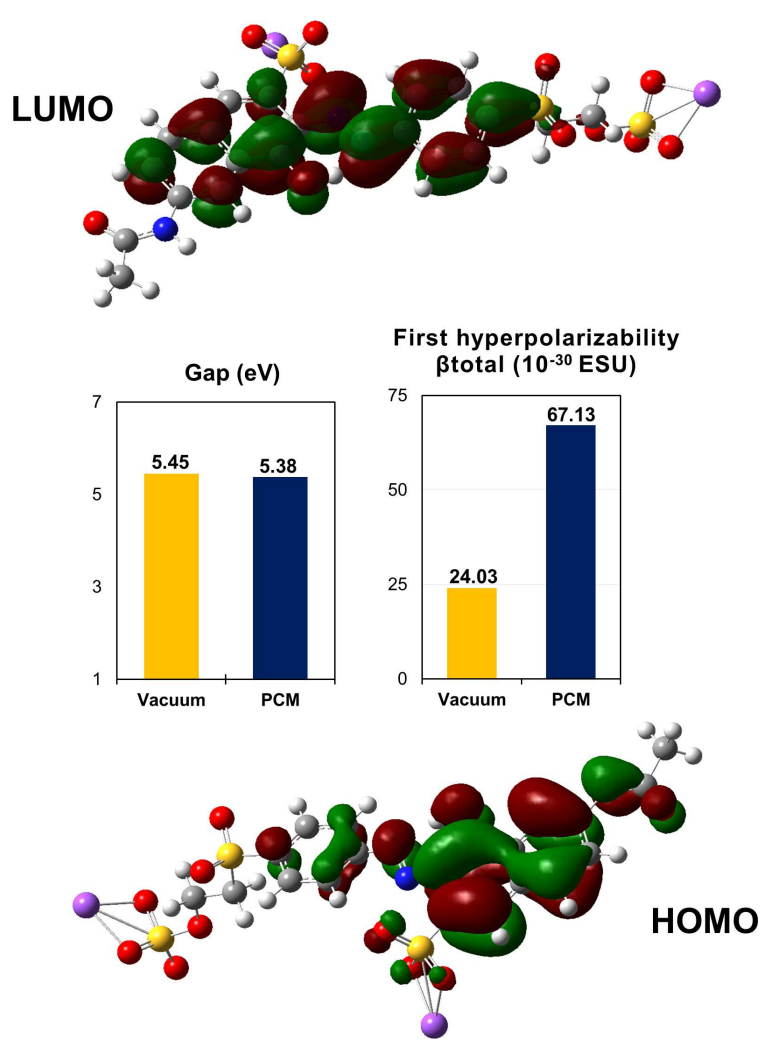

Fig. 4 The frontier molecular orbitals, energy gap and the values of the first hyperpolarizability at vacuum and solvent, obtained using the M06-2X DFT method coupled with the 6-311++G $(d, p)$ bais set and the C-PCM solvent model.

being the closest to the CAM-B3LYP prediction, and presenting a sensible improvement (ca. 168\%) concerning the B3LYP result.

Concerning other NLO materials, RO16 is quite competitive. For instance, according to the M06-2X prediction, the first hyperpolarizability predicted for $\mathrm{RO} 16\left(\beta_{\text {total }}=72.73 \times\right.$ $\left.10^{-30} \mathrm{esu}\right)$ is ca. 214 times greater that the value currently reported for urea $\left(\beta_{\text {total }}=0.34 \times 10^{-30}\right.$ esu $)[35,36]$, a well known optical material. Through individually presents low NLO response, this property is enhanced in crystal, once $\beta$ is an addictive parameter [73,74]. RO16 also presents a good performance concerning the para-nitro aniline molecule, which is other typical donor-acceptor compound with NLO applications that presents $\beta_{\text {total }}$ estimated between $6.27 \times 10^{-30}$ [75] and $8.86 \times 10^{-30}$ esu [76]. Thus, all results indicate RO16 is really suitable for optical applications.

Considering the contributions of the solvent, it is clear that the environment presents a powerful influence on the first hyperpolarizability. For instance, Table 3 shows the results obtained using the M06-2X functional in vacuum and water solvent, considering the C-PCM solvent model. From gas to solvent, the energy gap decreases from 5.10 to 5.02 eV. However, as Oudar and Chemla [77] have shown, the first hyperpolarizability is an inverse function of the energy- gap, being approximated like $\beta \propto \Delta \mu f / \Delta E^{3}$, where $f$ is the oscillator force corresponding to the energy transition and $\Delta \mu$ is the difference between the dipole moment in the excited and ground states. Quantitatively, Fig. 4 better explores the inverse relation between the first hyperpolarizability and the energy-gap. Thus, it is expected that a slight variation in the energy gap generates a considerable improvement in $\beta_{\text {total }}$. According to the M06-2X results, the first hyperpolarizability changes from $27.77 \times 10^{-30}$ to $72.73 \times 10^{-30} \mathrm{esu}$, showing an improvement of ca. $162 \%$ concerning the gasphase value.

\subsection{PDOS analysis}

The Partial Density of States (PDOS) is a function that brings reliable information about the electronic structure of the material [78-83]. To understand the individual contributions of specific atoms to PDOS and how their contributions change when those atoms are within a chemical group, the $\mathrm{O}$ and $\mathrm{N}$ atoms were analyzed individually, and their results were plotted against the chemical group curves as $\mathrm{Azo}(-\mathrm{N}=\mathrm{N}-)$, $\mathrm{SO}_{2}, \mathrm{C}$ rings, $\mathrm{SO}_{3} \mathrm{Na}$ (Position 1), and $\mathrm{SO}_{3} \mathrm{Na}$ (Position 2). The choice of $\mathrm{O}$ and $\mathrm{N}$ as isolated atoms is due to their high electronegativity and their presence in the main functional groups mentioned above. All the other atoms are majority $\mathrm{H}$ and were classified as Allothers. The results in the vacuum and under PCM implicit water solvent environment were compared.

Fig. 5, shows the contribution of isolated $\mathrm{O}$ and $\mathrm{N}$ atoms to the PDOS is low and has relevant values only in the region of occupied orbitals. This behavior does not change from vacuum to the implicit solvent environment. The Azo group has a significant contribution in the region of occupied orbitals and has a peak at the LUMO orbital, which means the HOMO-LUMO transition arises from the $\mathrm{C}$ rings to an orbital that has a component at the Azo group. The PDOS of the $\mathrm{SO}_{2}$ group has no appreciable change from vacuum to the implicit water environment. $\mathrm{C}$ rings have the most important contribution in PDOS. This effect occurs because aromatic rings present a great abundance of $\pi$ electrons, which are less bonded to the nuclei, being strongly polarizable by the environment. One can observe that the water compresses the peaks. In the region of virtual orbitals region, it is clear the tendency to unite the peaks close to 0.0 $\mathrm{eV}$. Observing these peaks around $3.0 \mathrm{eV}$, it is also possible to note this phenomenon. Fig. 5, shows the contribution of isolated $\mathrm{O}$ and $\mathrm{N}$ atoms to the DOS is low. They have relevant values only in the region of occupied orbitals. This behavior does not change from vacuum to water. The Azo group has a significant contribution in the region of occupied orbitals. It has a peak at the LUMO orbital, which means the HOMO-LUMO transition arises from the $\mathrm{C}$ rings to an orbital that has a component in the Azo group. The PDOS 


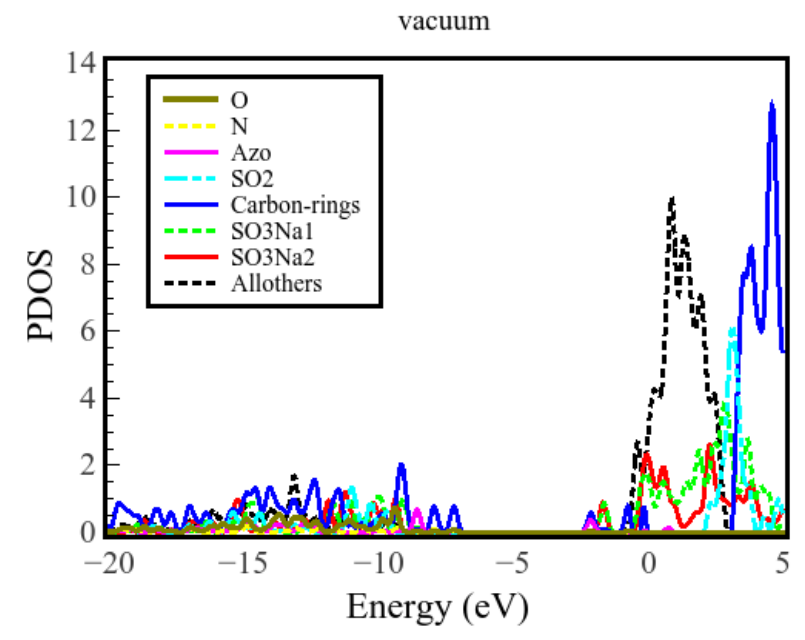

(a)

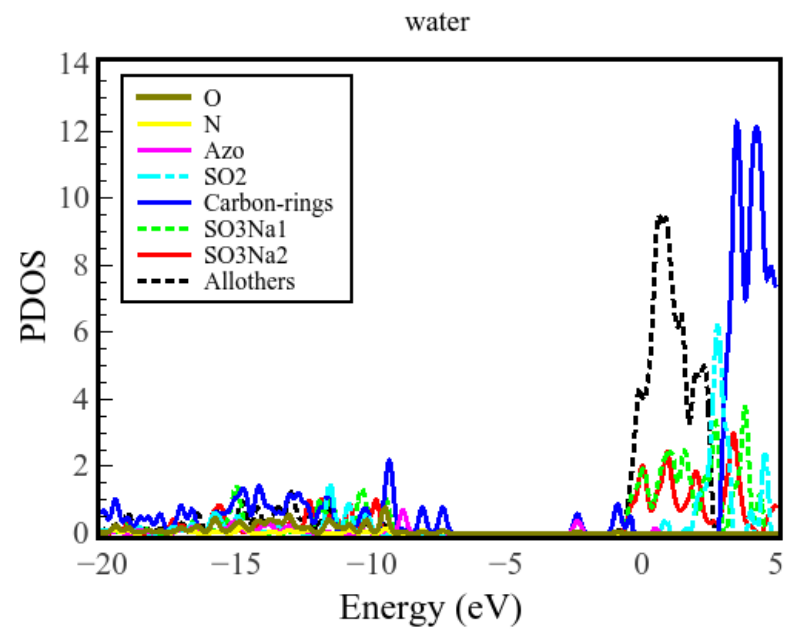

(b)

Fig. 5 The projected density of states (PDOS) at vacuum (a) and water solvent (b) calculated using the M06-2X/6-311++G $(d, p)$ level of quantum mechanics and the conducting version of the polarizable continuum model (C-PCM) for the solvent.

of the $\mathrm{SO}_{2}$ group has no appreciable change from vacuum to water. $\mathrm{C}$ rings have the major contribution in all PDOS plots. This effect occurs because aromatic rings present a great abundance of $\pi$ electrons, which are less bonded to the nuclei, being strongly polarizable by the environment. It can be observed that the implicit environment compresses the peaks. In the region of virtual orbitals, it is clear the tendency to unite the peaks close to $0.0 \mathrm{eV}$. Observing peaks around $3.0 \mathrm{eV}$, one can also note this phenomenon. They experience the tendency to merge their peaks in all spectra under the effects of the PCM water solvent.

\subsection{Reactivity}

\section{Global reactivity descriptors}

Table 4 shows the results obtained for the global reactivity descriptors obtained For the RO16 molecule. From these results, one can observe that the solvent plays a relevant in the molecular reactivity. For instance, analyzing the M06$2 \mathrm{X}$ data obtained at gas and solvent, one concludes that the chemical potential increases from $-4.58 \mathrm{eV}$ in vacuum to $-4.78 \mathrm{eV}$ in a solvent. The ionization potential (IP) and electron affinity (EA) increase to $7.29 \mathrm{eV}$ (ca. 2.24\%) and $2.27 \mathrm{eV}$ (ca. 12\%) in an aqueous environment. Consequently, the system becomes more reactive when embedded in a solvent. Concerning the chemical hardness $(\eta)$, this parameter decreases from $2.55 \mathrm{eV}$ (vacuum) to $2.51 \mathrm{eV}$ (solvent), but this effect is expected once there a inverse relation between $\eta$ and the dipole polarizability ( $\alpha)$ [25], which increases in the solvent.

The global electrophilicity $(\omega)$ and nucleophilicity $(N)$ are other two relevant reactive parameters often discussed for a pharmacy candidate. According to Domingos and collaborators, a chromophore can be classified as marginal $(x<$ $0.8 \mathrm{eV})$, moderate $(0.8 \leq x \leq 1.5 \mathrm{eV})$, or even as a strong electrophile $(x>1.5 \mathrm{eV})$ [84]. Similarly, a compound can be assigned as marginal $(N<2.0 \mathrm{eV})$, moderate $(2.0 \leq N \leq$ $3.0 \mathrm{eV})$, and a strong nucleophile $(N>3.0 \mathrm{eV})[56,57]$. After considering these scales, one observes that the environment increases the electrophilicity from $4.11 \mathrm{eV}$ to 4.55 $\mathrm{eV}$, which allows to classify RO16 as a strong electrophile. However, one observes a contrary behavior for the nucleophilicity. From vacuum to solvent, $N$ varies from $3.77 \mathrm{eV}$ to $2.11 \mathrm{eV}$, changing the status from a strong to moderate nucleophile.

One can also observe that the absence of LC and HFE contributions overestimates $\omega$. For instance, from B3LYP to CAM-B3LYP, one obtains $\omega=6.68 \mathrm{eV}$ and $\omega=4.02 \mathrm{eV}$, respectively. Similar behavior is observed between M06-L $(\omega=9.97 \mathrm{eV})$ and M06-2X $(\omega=4.55 \mathrm{eV})$. These findings show that LC and HFE are essentials one desires to investigate the molecular reactivity. Regarding nucleophilicity, these interactions also are fundamentals. However, they actuate, decreasing the values of $N$. For instance, while B3LYP predicts $2.98 \mathrm{eV}$, the CAM-B3LYP method indicates 4.46 $\mathrm{eV}$ for $N$. Again, similar behavior is observed for M06-L and M06-2X, for instance.

\section{Local reactivity descriptors}

After determining the global reactivity parameters, the next step is to discover the independent behavior of each atomic site in the molecule. Figure 6 presents the plots for the relative nucleophilic and electrophilic indexes $\left(f_{\mathrm{nu}}, f_{\mathrm{el}}\right)$ obtained 
Table 4 The global reactivity descriptors, the chemical potential $(\mu)$, ionization energy (IP), electron affinity (EA), chemical hardness $(\eta)$, electrophilicity $(\omega)$, and nucleophilicity $(N)$. All results are in $\mathrm{eV}$ and were calculated for different degrees of quantum chemistry and the 6$311++\mathrm{G}(d, p)$ basis set:

\begin{tabular}{lllllll}
\hline QM & $\mu$ & IP & EA & $\eta$ & $\omega$ & $N$ \\
\hline B3LYP & -4.57 & 6.08 & 3.05 & 1.52 & 6.88 & 2.98 \\
CAM-B3LYP & -4.65 & 7.34 & 1.96 & 2.69 & 4.02 & 4.46 \\
M06-L & -4.46 & 5.45 & 3.46 & 1.00 & 9.97 & 2.94 \\
M06 & -4.65 & 6.36 & 2.94 & 1.71 & 6.32 & 4.14 \\
M06-2X & -4.78 & 7.29 & 2.27 & 2.51 & 4.55 & 2.11 \\
M06-2X (Gas) & -4.58 & 7.13 & 2.03 & 2.55 & 4.11 & 3.77 \\
M06-HF & -5.12 & 8.97 & 1.26 & 3.86 & 3.39 & 3.31 \\
PM6 & -5.34 & 8.83 & 1.85 & 3.49 & 4.09 & 1.60 \\
\hline
\end{tabular}

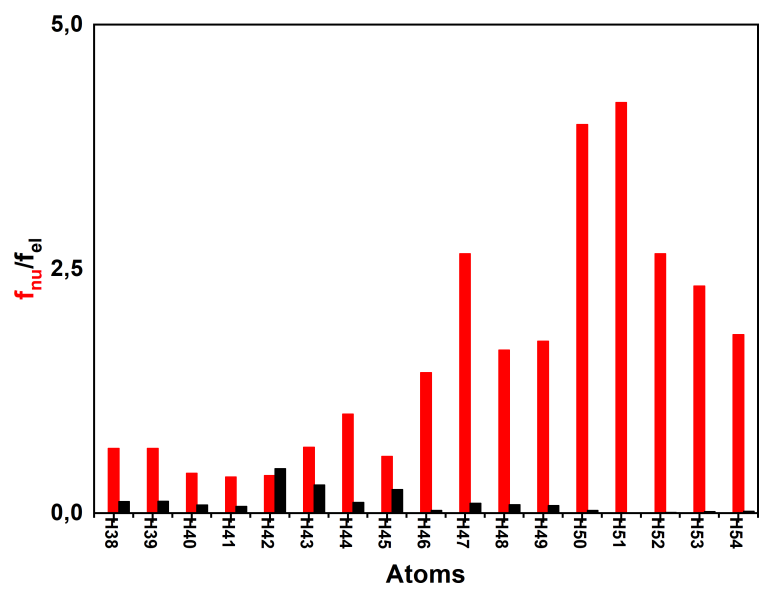

(a)

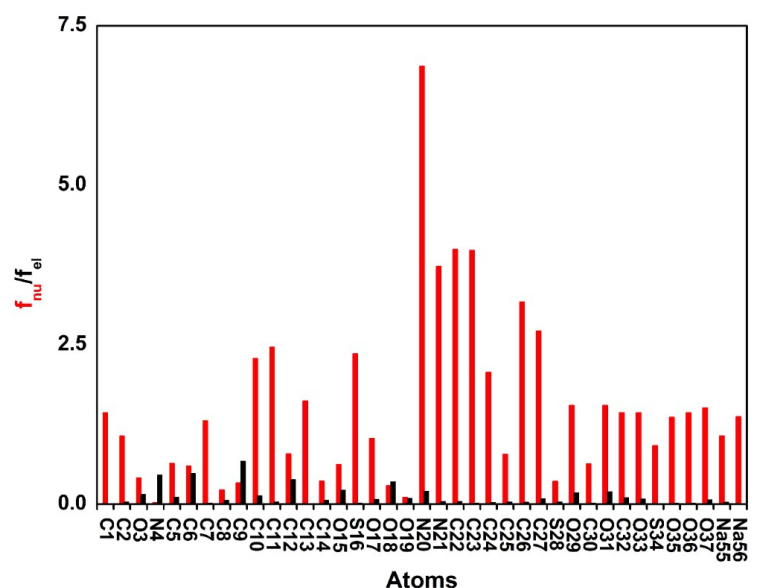

(b)

Fig. 6 (a) Bar graphic of relative nucleophilicity $f_{\text {nu }}$ (red) and relative electrophilicity $f_{\mathrm{el}}$ (black) for $\mathrm{H}$ (b) and $\mathrm{C}, \mathrm{N}, \mathrm{O}, \mathrm{S}$, and $\mathrm{Na}$ atoms (c) calculated at the M06-2X/6-311++G $(d, p)$ level of quantum mechanics.

from the Fukui functions $\left(F_{k}^{+}, F_{k}^{-}\right)$calculated from the Mullikan charges at the M06-2X/6-311++G $(d, p)$ level of theory.

As one can observe from Fig. $6 \mathrm{~b}$, the hydrogen atoms present a nucleophilic behavior, which shows that these atomic sites prefer to interact with electrophilic atoms. The excep- tions are hydrogen atoms $(\mathrm{H} 42, \mathrm{H} 43$, and $\mathrm{H} 45)$ bonded to benzene rings.

On the other hand, Fig. 6c allows understanding the behavior of $\mathrm{C}, \mathrm{N}, \mathrm{O}, \mathrm{S}$, and $\mathrm{Na}$ atoms. Again, the behavior of the material is mostly nucleophilic. In particular, most cites present $f_{\text {nu }}<2.5$. However, the $\mathrm{C} 10, \mathrm{C} 26$, and $\mathrm{C} 26$ in the benzene ring, $\mathrm{C} 11$ in phenol ring, N21 in the azo bond, $\mathrm{C} 22, \mathrm{C} 23$. The major nucleophilic behavior $\left(f_{\mathrm{nu}}>5.0\right)$ is observed for N20. The unique exceptions are N4, C9, and $\mathrm{O} 18$, in which $f_{\mathrm{el}}>f_{\text {nu }}$.

\section{Conclusions}

Based on DFT/TD-DFT and semiempirical methods, this works presents a theoretical and experimental discussion of the optical and reactive properties of the reactive orange 16 dye. These results accounts for solvent contributions, longrange (LC) and Hartree-Fock exchange (HFE) corrections.

In the ground state, RO16 presents a wide absorption band placed in the visible region of the spectra. Clearly, this band is composed of four strong $\pi \rightarrow \pi^{*}$ excitations, besides a weak $n \rightarrow \pi^{*}$ line placed in the low-lying region of the spectra. Although the $\pi \rightarrow \pi^{*}$ absorption suffers a clear redshift when embedded in a water solvent, the $n \rightarrow \pi^{*}$ state presents a smooth blue shift. However, this behavior only is correctly described if long-range interactions under the form of Hartree-Fock exchange or dispersion corrections are considered in the calculations.

The theoretical results also show that RO16 can be useful for a variety of NLO applications. In fact, according to DFT and semi-empirical calculations, the chromophore presents a strong NLO response. For instance, static approximations of the first-hyperpolarizability $\left(\beta_{\text {total }}\right)$ indicate values superior to those reported for standard NLO materials like $p$-nitroaniline and urea. Moreover, the current DFT calculations using the Lorentz-Lorenz equation, which connects the dipole polarizability $(\alpha)$ to the refractive index $(n)$, show that the RO16 molecule presents lower $n$. However, those methods which do not account for LC or HFE do not describe the reality, overestimating the dipole polarizability, the refractive index, and the first-hyperpolarizability. Thus, such interactions are essential to better understand the NLO response of the RO16 molecule.

\section{Author Declarations}

\section{Funding:}

Sãvio Fonseca, and Regina Pereira have been supported by CAPES (Coordenação de Aperfeiçoamento de Pessoal de Nível Superior). Lucas Modesto-Costa has been supported by FAPESPA (Fundação Amazônica de Amparo a Estudos e 
Pesquisas). Francisco A. O. Carvalho and Tarciso AndradeFilho have been supported by $\mathrm{CNPq}$ (Conselho Nacional de Desenvolvimento Científico e Tecnológico). Antônio R. da Cunha has been supported by FAPEMA (Fundação de Amparo à Pesquisa e ao Desenvolvimento Científico e Tecnológico do Maranhão) and FAPESP (Fundação de Amparo à Pesquisa do Estado de São Paulo).

\section{Conflicts of interest/Competing interests:}

The authors declare no competing interests.

\section{Availability of data and material:}

Not applicable.

\section{Code availability:}

Not applicable.

\section{Authors' contributions:}

Sávio Fonseca: Electronic structure calculations. Lucas Santos: Experimental data acquisition. Regina Pereira: Experimental data acquisition. Lucas Modesto-Costa: Electronic structure calculations. Antônio R. da Cunha: Formal analysis, Writing - original draft. Marcelo R.S. Siqueira: Formal analysis, Writing - original draft. Francisco A. O. Carvalho: Formal analysis, Writing - original draft. Tarciso Andrade-Filho: Writing - original draft, Writing - review editing. Rodrigo Gester: Writing - original draft, Writing - review editing, Supervision.

\section{References}

1. P.A. Franken, A.E. Hill, C.W. Peters, G. Weinreich, Generation of optical harmonics, Phys. Rev. Lett. 7, 118 (1961). DOI 10.1103/PhysRevLett.7.118

2. P.S. Lin, Y. Shoji, S.N. Afraj, M. Ueda, C.H. Lin, S. Inagaki, T. Endo, S.H. Tung, M.C. Chen, C.L. Liu, T. Higashihara, Controlled synthesis of poly[(3-alkylthio)thiophene]s and their application to organic field-effect transistors, ACS Applied Materials \& Interfaces 13, 31898 (2021). DOI 10.1021/acsami.1c04404

3. A. Sebastian, R. Pendurthi, T.H. Choudhury, J.M. Redwing, S. Das, Benchmarking monolayer MoS2 and WS2 fieldeffect transistors, Nature Communications 12 (2021). DOI 10.1038/s41467-020-20732-w

4. H. Belaidi, S. Belaidi, C. Katan, C. Latouche, A. Boucekkine, Vibronic coupling to simulate the phosphorescence spectra of ir(III)based OLED systems: TD-DFT results meet experimental data, Journal of Molecular Modeling 22 (2016). DOI 10.1007/s00894016-3132-8
5. K. Uzun, S. Sayın, O. Tamer, U. Çevik, Comparison of charge transport and opto-electronic properties of pyrene and anthracene derivatives for OLED applications, Journal of Molecular Modeling 27 (2021). DOI 10.1007/s00894-021-04793-2

6. Y. Bouzineb, A. Slimi, M. Raftani, A. Fitri, A.T. Benjelloun, M. Benzakour, M. Mcharfi, M. Bouachrine, Theoretical study of organic sensitizers based on 2, 6-diphenyl-4h-pyranylidene/1, 3, 4-oxadiazole for dye-sensitized solar cells, Journal of Molecular Modeling 26 (2020). DOI 10.1007/s00894-020-04611-1

7. Z. Afzal, R. Hussain, M.U. Khan, M. Khalid, J. Iqbal, M.U. Alvi, M. Adnan, M. Ahmed, M.Y. Mehboob, M. Hussain, C.J. Tariq, Designing indenothiophene-based acceptor materials with efficient photovoltaic parameters for fullerene-free organic solar cells, Journal of Molecular Modeling 26 (2020). DOI 10.1007/s00894020-04386-5

8. A.R.K. Selvaraj, S. Hayase, Molecular dynamics simulations on the aggregation behavior of indole type organic dye molecules in dye-sensitized solar cells, Journal of Molecular Modeling 18, 2099 (2011). DOI 10.1007/s00894-011-1230-1

9. B.H. Barboza, O.P. Gomes, A. Batagin-Neto, Polythiophene derivatives as chemical sensors: a DFT study on the influence of side groups, Journal of Molecular Modeling 27 (2021). DOI 10.1007/s00894-020-04632-w

10. A.A. Safonov, E.A. Rykova, A.A. Bagaturyants, V.A. Sazhnikov, M.V. Alfimov, Atomistic simulations of materials for optical chemical sensors: DFT-d calculations of molecular interactions between gas-phase analyte molecules and simple substrate models, Journal of Molecular Modeling 17, 1855 (2010). DOI 10.1007/s00894-010-0882-6

11. T. Schneider, Nonlinear Optics in Telecommunications (Springer Berlin Heidelberg, 2004). DOI 10.1007/978-3-662-08996-5

12. Z. Gao, Y. Hao, M. Zheng, Y. Chen, A fluorescent dye with large stokes shift and high stability: synthesis and application to live cell imaging, RSC Advances 7, 7604 (2017). DOI $10.1039 / \mathrm{c} 6 \mathrm{ra2} 7547 \mathrm{~h}$

13. K. Huang, X. Jiao, C. Liu, Q. Wang, X. Qiu, S. He, L. Zhao, $\mathrm{X}$. Zeng, Synthesis of a novel -extended hybrid rhodamine dye with far-red fluorescence emission and its application in bioimaging, Dyes and Pigments 145, 561 (2017). DOI 10.1016/j.dyepig.2017.06.047

14. Y. Orozco-Gonzalez, C. Bistafa, S. Canuto, Solvent effect on the stokes shift and on the nonfluorescent decay of the daidzein molecular system, The Journal of Physical Chemistry A 117, 4404 (2013). DOI 10.1021/jp4021646

15. K. Coutinho, S. Canuto, The sequential monte carlo-quantum mechanics methodology. application to the solvent effects in the stokes shift of acetone in water, Journal of Molecular Structure: THEOCHEM 632, 235 (2003). DOI 10.1016/s01661280(03)00302-6

16. V. Manzoni, R. Gester, A.R. da Cunha, T. Andrade-Filho, R. Gester, Solvent effects on stokes shifts, and NLO response of thieno[3, 4-b]pyrazine: A comprehensive QM/MM investigation, Journal of Molecular Liquids 335, 115996 (2021). DOI 10.1016/j.molliq.2021.115996

17. C. Shruthi, V. Ravindrachary, B. Guruswamy, D.J. Prasad, J. Goveas, K. Kumara, N. Lokanath, Molecular structure, hirshfeld surface and density functional theoretical analysis of a NLO active chalcone derivative single crystal-a quantum chemical approach, Journal of Molecular Structure 1228, 129739 (2021). DOI 10.1016/j.molstruc.2020.129739

18. T. Zhao, C. Wang, S. Hu, S. Ji, C. Hu, K. Xu, B. Teng, Structural design and characterization of a chalcone derivative crystal DAMO with strong SHG efficiency for NLO applications, Optical Materials 112, 110765 (2021). DOI 10.1016/j.optmat.2020.110765

19. H. Guo, L. Jiang, K. Huang, R. Wang, S. Liu, Z. Li, X. Rong, G. Dong, Unsymmetric squaraine for narrow band green-selective 
organic photodetectors, Organic Electronics 92, 106122 (2021). DOI 10.1016/j.orgel.2021.106122

20. Q. Xiao, X. Zhu, J. He, M. Xie, Y. Zhou, Z. Li, Photostable squaraine dimers for organic solar cells with a high open circuit voltage exceeding 1.0 v, Dyes and Pigments 194, 109633 (2021). DOI 10.1016/j.dyepig.2021.109633

21. P. Hohenberg, W. Kohn, Inhomogeneous electron gas, Phys. Rev. 136, B864 (1964). DOI 10.1103/physrev.136.b864

22. W. Kohn, L.J. Sham, Self-consistent equations including exchange and correlation effects, Phys. Rev. 140, A1133 (1965). DOI 10.1103/physrev.140.a1133

23. A.C.M. Pimenta, T. Andrade-Filho, V. Manzoni, J.D. Nero, R. Gester, Giant values obtained for first hyperpolarizabilities of methyl orange: a DFT investigation, Theor. Chem. Acc. 138 (2019). DOI 10.1007/s00214-018-2406-x

24. R. Gester, A. Torres, C. Bistafa, R.S. Araújo, T.A. da Silva, V. Manzoni, Theoretical study of a recently synthesized azo dyes useful for OLEDs, Materials Letters 280, 128535 (2020). DOI 10.1016/j.matlet.2020.128535

25. R. Gester, A. Torres, A.R. da Cunha, T. Andrade-Filho, V. Manzoni, Theoretical study of thieno[3, 4-b]pyrazines derivatives with enhanced NLO response, Chemical Physics Letters p. 138976 (2021). DOI 10.1016/j.cplett.2021.138976

26. T. Andrade-Filho, T. Silva, E. Belo, A. Raiol, R.V. de Oliveira, P.S. Marinho, H.R. Bitencourt, A.M. Marinho, A.R. da Cunha, R. Gester, Insights and modelling on the nonlinear optical response, reactivity, and structure of chalcones and dihydrochalcones, Journal of Molecular Structure 1246, 131182 (2021). DOI 10.1016/j.molstruc.2021.131182

27. A. Raiol, A.R. da Cunha, V. Manzoni, T. Andrade-Filho, R. Gester, Solvent enhancement and isomeric effects on the NLO properties of a photoinduced cis-trans azomethine chromophore: A sequential MC/QM study, Journal of Molecular Liquids $p$. 116887 (2021). DOI 10.1016/j.molliq.2021.116887

28. V. Manzoni, L. Modesto-Costa, J.D. Nero, T. Andrade-Filho, R. Gester, Strong enhancement of NLO response of methyl orange dyes through solvent effects: A sequential monte carlo/DFT investigation, Optical Materials 94, 152 (2019). DOI 10.1016/j.optmat.2019.05.018

29. M.N. Khan, D.K. Parmar, D. Das, Recent applications of azo dyes: A paradigm shift from medicinal chemistry to biomedical sciences, Mini-Reviews in Medicinal Chemistry 21, 1071 (2021). DOI 10.2174/1389557520999201123210025

30. F.F. Albelwi, M. Al-anazi, A. Naqvi, Z.M. Hritani, R.M. Okasha, T.H. Afifi, M. Hagar, Novel oxazolones incorporated azo dye: Design, synthesis photophysical-DFT aspects and antimicrobial assessments with in-silico and in-vitro surveys, Journal of Photochemistry and Photobiology 7, 100032 (2021). DOI 10.1016/j.jpap.2021.100032

31. Y. El-Sayed, M. Gaber, N. El-Wakeil, ahmed abdelaziz, A. ElNagar, Metal complexes of azo mesalamine drug: Synthesis, characterization, and their application as an inhibitor of pathogenic fungi, Applied Organometallic Chemistry 35 (2021). DOI $10.1002 /$ aoc. 6290

32. M. Malakootian, M.R. Heidari, Reactive orange 16 dye adsorption from aqueous solutions by psyllium seed powder as a lowcost biosorbent: kinetic and equilibrium studies, Applied Water Science 8 (2018). DOI 10.1007/s13201-018-0851-2

33. M.F. Hanafi, N. Sapawe, A review on the water problem associate with organic pollutants derived from phenol, methyl orange, and remazol brilliant blue dyes, Materials Today: Proceedings 31, A141 (2020). DOI 10.1016/j.matpr.2021.01.258

34. A.S. Abdulhameed, A.T. Mohammad, A.H. Jawad, Application of response surface methodology for enhanced synthesis of chitosan tripolyphosphate/TiO2 nanocomposite and adsorption of reactive orange 16 dye, Journal of Cleaner Production 232, 43 (2019). DOI 10.1016/j.jclepro.2019.05.291
35. M.J. Alam, A.U. Khan, M. Alam, S. Ahmad, Spectroscopic (FTIR, FT-raman, 1H NMR and UV-vis) and DFT/TD-DFT studies on cholesteno $[4,6-b, c]-2^{\prime}, 5^{\prime}$-dihydro- $1^{\prime}, 5^{\prime}$-benzothiazepine, Journal of Molecular Structure 1178, 570 (2019). DOI 10.1016/j.molstruc.2018.10.063

36. H. Abbas, M. Shkir, S. AlFaify, Density functional study of spectroscopy, electronic structure, linear and nonlinear optical properties of 1-proline lithium chloride and 1-proline lithium bromide monohydrate: For laser applications, Arabian Journal of Chemistry 12, 2336 (2019). DOI 10.1016/j.arabjc.2015.02.011

37. T. Yanai, D.P. Tew, N.C. Handy, A new hybrid exchange-correlation functional using the coulomb-attenuating method (CAM-b3lyp), Chemical Physics Letters 393, 51 (2004). DOI 10.1016/j.cplett.2004.06.011

38. T. Clark, J. Chandrasekhar, G.W. Spitznagel, P.V.R. Schleyer, Efficient diffuse function-augmented basis sets for anion calculations. III. the 3-21g basis set for first-row elements, li-f, Journal of Computational Chemistry 4, 294 (1983). DOI 10.1002/jcc.540040303

39. M.M. Francl, W.J. Pietro, W.J. Hehre, J.S. Binkley, M.S. Gordon, D.J. DeFrees, J.A. Pople, Self-consistent molecular orbital methods. XXIII. a polarization-type basis set for second-row elements, The Journal of Chemical Physics 77, 3654 (1982). DOI $10.1063 / 1.444267$

40. R. Krishnan, J.S. Binkley, R. Seeger, J.A. Pople, Self-consistent molecular orbital methods. XX. a basis set for correlated wave functions, The Journal of Chemical Physics 72, 650 (1980). DOI $10.1063 / 1.438955$

41. A.D. McLean, G.S. Chandler, Contracted gaussian basis sets for molecular calculations. i. second row atoms, $\mathrm{z}=11-18$, The Journal of Chemical Physics 72, 5639 (1980). DOI 10.1063/1.438980

42. G.W. Spitznagel, T. Clark, P. von Ragué Schleyer, W.J. Hehre, An evaluation of the performance of diffuse function-augmented basis sets for second row elements, na-cl, Journal of Computational Chemistry 8, 1109 (1987). DOI 10.1002/jcc.540080807

43. A.D. Becke, Density-functional exchange-energy approximation with correct asymptotic behavior, Physical Review A 38, 3098 (1988). DOI 10.1103/physreva.38.3098

44. C. Lee, W. Yang, R.G. Parr, Development of the collesalvetti correlation-energy formula into a functional of the electron density, Physical Review B 37, 785 (1988). DOI 10.1103/physrevb.37.785

45. Y. Zhao, D.G. Truhlar, A new local density functional for maingroup thermochemistry, transition metal bonding, thermochemical kinetics, and noncovalent interactions, The Journal of Chemical Physics 125, 194101 (2006). DOI 10.1063/1.2370993

46. Y. Zhao, D.G. Truhlar, The m06 suite of density functionals for main group thermochemistry, thermochemical kinetics, noncovalent interactions, excited states, and transition elements: two new functionals and systematic testing of four m06-class functionals and 12 other functionals, Theoretical Chemistry Accounts 120, 215 (2007). DOI 10.1007/s00214-007-0310-x

47. Y. Zhao, D.G. Truhlar, The m06 suite of density functionals for main group thermochemistry, thermochemical kinetics, noncovalent interactions, excited states, and transition elements: two new functionals and systematic testing of four m06-class functionals and 12 other functionals, Theoretical Chemistry Accounts 120, 215 (2007). DOI 10.1007/s00214-007-0310-x

48. Y. Zhao, D.G. Truhlar, Density functional for spectroscopy: no long-range self-interaction error, good performance for rydberg and charge-transfer states, and better performance on average than b3lyp for ground states, The Journal of Physical Chemistry A 110, 13126 (2006). DOI 10.1021/jp066479k

49. R. Vijayaraj, V. Subramanian, P.K. Chattaraj, Comparison of global reactivity descriptors calculated using various density functionals: A QSAR perspective, Journal of Chemical Theory and Computation 5, 2744 (2009). DOI 10.1021/ct900347f 
50. L. Lescos, S.P. Sitkiewicz, P. Beaujean, M. Blanchard-Desce, B. Champagne, E. Matito, F. Castet, Performance of DFT functionals for calculating the second-order nonlinear optical properties of dipolar merocyanines, Physical Chemistry Chemical Physics 22, 16579 (2020). DOI 10.1039/d0cp02992k

51. J.J.P. Stewart, Optimization of parameters for semiempirical methods v: Modification of NDDO approximations and application to 70 elements, Journal of Molecular Modeling 13, 1173 (2007). DOI 10.1007/s00894-007-0233-4

52. H.A. Lorentz, Ueber die beziehung zwischen der fortpflanzungsgeschwindigkeit des lichtes und der körperdichte, Annalen der Physik 245, 641 (1880). DOI https://doi.org/10.1002/andp.18802450406

53. L. Lorenz, Ueber die refractionsconstante, Annalen der Physik 247, 70 (1880). DOI https://doi.org/10.1002/andp.18802470905

54. D.A. Kleinman, Nonlinear dielectric polarization in optical media, Phys. Rev. 126, 1977 (1962). DOI 10.1103/PhysRev.126.1977

55. N.E.H. Bensiradj, A. Dekhira, N. Zouaghi, O. Ouamerali, DFT and TDDFT study of chemical reactivity and spectroscopic properties of $\mathrm{M}(\mathrm{TePh}) 2$ [TMEDA] $\mathrm{M}=\mathrm{Zn}, \mathrm{Cd}$, and $\mathrm{Hg}$ complexes, Structural Chemistry 31(4), 1493 (2020). DOI 10.1007/s11224020-01509-9

56. L.R. Domingo, E. Chamorro, P. Pérez, Understanding the reactivity of captodative ethylenes in polar cycloaddition reactions. a theoretical studyt, The Journal of Organic Chemistry 73, 4615 (2008). DOI 10.1021/jo800572a

57. P. Jaramillo, L.R. Domingo, E. Chamorro, P. Pérez, A further exploration of a nucleophilicity index based on the gas-phase ionization potentials, Journal of Molecular Structure: THEOCHEM 865, 68 (2008). DOI 10.1016/j.theochem.2008.06.022

58. R. Hazarika, B. Kalita, Elucidating the therapeutic activity of selective curcumin analogues: DFT-based reactivity analysis, Structural Chemistry 32, 1701 (2021). DOI 10.1007/s11224-02101745-7

59. W. Yang, W.J. Mortier, The use of global and local molecular parameters for the analysis of the gas-phase basicity of amines, Journal of the American Chemical Society 108, 5708 (1986). DOI 10.1021/ja00279a008

60. D. Manna, T.K. Ghanty, Complexation behavior of trivalent actinides and lanthanides with 1, 10-phenanthroline-2, 9dicarboxylic acid based ligands: insight from density functional 74 theory, Physical Chemistry Chemical Physics 14, 11060 (2012). DOI $10.1039 / \mathrm{c} 2 \mathrm{cp} 40083 \mathrm{a}$

61. R.K. Roy, S. Krishnamurti, P. Geerlings, S. Pal, Local softness and hardness based reactivity descriptors for predicting intra- 75 . and intermolecular reactivity sequences: Carbonyl compounds, The Journal of Physical Chemistry A 102, 3746 (1998). DOI 10.1021/jp973450v

62. R.K. Roy, F. de Proft, P. Geerlings, Site of protonation in aniline and substituted anilines in the gas phase: A study via the local 76. hard and soft acids and bases concept, The Journal of Physical Chemistry A 102, 7035 (1998). DOI 10.1021/jp9815661

63. M.J. Frisch, G.W. Trucks, H.B. Schlegel, G.E. Scuseria, M.A. Robb, J.R. Cheeseman, G. Scalmani, V. Barone, G.A. Petersson, H. Nakatsuji, X. Li, M. Caricato, A. Marenich, J. Bloino, 77 . B.G. Janesko, R. Gomperts, B. Mennucci, H.P. Hratchian, J.V. Ortiz, A.F. Izmaylov, J.L. Sonnenberg, D. Williams-Young, F. Ding, F. Lipparini, F. Egidi, J. Goings, B. Peng, A. Petrone, T. Hender- 78 son, D. Ranasinghe, V.G. Zakrzewski, J. Gao, N. Rega, G. Zheng, W. Liang, M. Hada, M. Ehara, K. Toyota, R. Fukuda, J. Hasegawa, M. Ishida, T. Nakajima, Y. Honda, O. Kitao, H. Nakai, T. Vreven, K. Throssell, J.A. Montgomery, Jr., J.E. Peralta, F. Ogliaro, 79 M. Bearpark, J.J. Heyd, E. Brothers, K.N. Kudin, V.N. Staroverov, T. Keith, R. Kobayashi, J. Normand, K. Raghavachari, A. Rendell, J.C. Burant, S.S. Iyengar, J. Tomasi, M. Cossi, J.M. Millam, M. Klene, C. Adamo, R. Cammi, J.W. Ochterski, R.L. Martin,
K. Morokuma, O. Farkas, J.B. Foresman, , D.J. Fox. Gaussian 09, Revision A.02 (2016). Gaussian Inc. Wallingford CT

64. J. Mitrovic, M. Radovic, D. Bojic, T. Andjelkovic, M. Purenovic, A. Bojic, Decolorization of textile azo dye reactive orange 16 with UV/h2o2 process, Journal of the Serbian Chemical Society 77, 465 (2012). DOI 10.2298/jsc110216187m

65. L. Gomes, D.W. Miwa, G.R.P. Malpass, A.J. Motheo, Electrochemical degradation of the dye reactive orange 16 using electrochemical flow-cell, Journal of the Brazilian Chemical Society 22, 1299 (2011). DOI 10.1590/s0103-50532011000700015

66. M. Catanho, G.R.P. Malpass, A. de Jesus Motheo, Avaliação dos tratamentos eletroquímico e fotoeletroquímico na degradação de corantes têxteis, Química Nova 29, 983 (2006). DOI $10.1590 / \mathrm{s} 0100-40422006000500018$

67. M.V.A. Damasceno, V. Manzoni, L. Modesto-Costa, G.M. Moura, J.D. Nero, A. Torres, R. Gester, Solvent effects on low-lying absorptions and vibrational spectra of thieno[3, 4-b]pyrazines: the role of unconventional $\mathrm{c}-\mathrm{h} \cdots \mathrm{n}$ bonds, Chemical Papers 73, 1519 (2019). DOI 10.1007/s11696-019-00703-2

68. R. Gester, M.V. Damasceno, S. Canuto, V. Manzoni, A theoretical study of the magnetic shielding of $15 \mathrm{n}$ of formamide in liquid water, Journal of Molecular Liquids 320, 114415 (2020). DOI 10.1016/j.molliq.2020.114415

69. R.M. Gester, H.C. Georg, T.L. Fonseca, P.F. Provasi, S. Canuto, in Marco Antonio Chaer Nascimento (Springer Berlin Heidelberg, 2012), pp. 117-124. DOI 10.1007/978-3-642-41163-2 1

70. R.M. Gester, C. Bistafa, H.C. Georg, K. Coutinho, S. Canuto, Theoretically describing the $17 \mathrm{o}$ magnetic shielding constant of biomolecular systems: uracil and 5-fluorouracil in water environment, Theoretical Chemistry Accounts 133 (2013). DOI 10.1007/s00214-013-1424-y

71. C. Valverde, F.A. Osório, T.L. Fonseca, B. Baseia, DFT study of thirdorder nonlinear susceptibility of a chalcone crystal, Chemical Physics Letters pp. 170-174 (2018). DOI 10.1016/j.cplett.2018.06.001

72. I. Hodgkinson, Q. hong Wu, J. Hazel, Empirical equations for the principal refractive indices and column angle of obliquely deposited films of tantalum oxide, titanium oxide, and zirconium oxide, Applied Optics 37, 2653 (1998). DOI 10.1364/ao.37.002653

3. K. Wu, J.G. Snijders, C. Lin, Reinvestigation of hydrogen bond effects on the polarizability and hyperpolarizability of urea molecular clusters, The Journal of Physical Chemistry B 106, 8954 (2002). DOI 10.1021/jp014181i

. G.T. Yu, W. Chen, F.L. Gu, Y. Aoki, Theoretical study on nonlinear optical properties of the li[calix[4]pyrrole]li-dimer, trimer and its polymer with diffuse excess electrons, Journal of Computational Chemistry pp. NA-NA (2009). DOI 10.1002/jcc. 21373

S. Muhammad, A.G. Al-Sehemi, Z. Su, H. Xu, A. Irfan, A.R. Chaudhry, First principles study for the key electronic, optical and nonlinear optical properties of novel donor-acceptor chalcones, Journal of Molecular Graphics and Modelling 72, 58 (2017). DOI 10.1016/j.jmgm.2016.12.009

S. Muhammad, A.G. Al-Sehemi, A. Irfan, A.R. Chaudhry, H. Gharni, S. AlFaify, M. Shkir, A.M. Asiri, The impact of position and number of methoxy group(s) to tune the nonlinear optical properties of chalcone derivatives: a dual substitution strategy, Journal of Molecular Modeling 22 (2016). DOI 10.1007/s00894-016-2946-8

J.L. Oudar, D.S. Chemla, Hyperpolarizabilities of the nitroanilines and their relations to the excited state dipole moment, The Journal of Chemical Physics 66, 2664 (1977). DOI 10.1063/1.434213

. L. Zhang, K. Xu, Understanding substitution effects on dye structures and optoelectronic properties of molecular halide perovskite cs $4 \mathrm{mx} 6$ $(\mathrm{m}=\mathrm{pb}, \mathrm{sn}, \mathrm{ge} \mathrm{x}=\mathrm{br}, \mathrm{i}, \mathrm{cl})$, Journal of Molecular Graphics and Modelling 91, 172 (2019). DOI 10.1016/j.jmgm.2019.06.009

D.F. Ferreira, W.D. Oliveira, E. Belo, R. Gester, M.R. Siqueira, A.M. Neto, J.D. Nero, Electron scattering processes in steroid molecules via NEGF-DFT: The opening of conduction channels by central oxygen, Journal of Molecular Graphics and Modelling 101, 107755 (2020). DOI 10.1016/j.jmgm.2020.107755 
80. Jogender, B. Badhani, Mandeep, R. Kakkar, A DFT-d2 study on the adsorption of phosgene derivatives and chloromethyl chloroformate on pristine and fe4-decorated graphene, Journal of Molecular Graphics and Modelling 101, 107754 (2020). DOI 10.1016/j.jmgm.2020.107754

81. A.M. Rodrigues, A.R. Palheta-Júnior, M.S.S. Pinheiro, A.M.R. Marinho, A.M.J. Chaves-Neto, R. Gester, T. Andrade-Filho, Encapsulation ability of silicon carbide and boron nitride nanotubes for spilanthol molecule, J. Nanostruc. Chem. 11, 203 (2020)

82. H.A. de Souza Freitas, A.M.C. Neto, F.F. de Sousa, R.G. Amorim, R. Gester, S.R. Stoyanov, A.R. Rocha, T. Andrade-Filho, Hydrationdependent band gap tunability of self-assembled phenylalanyl tryptophan nanotubes, Phys. E: Low-Dimens. Syst. Nanostructures 134, $114910(2021)$

83. E. Santana, R. Possa, A. Novais, V. Manzoni, E. Novais, T. Martins, R. Gester, T. Andrade-Filho, Adsorption study of 4-nitrophenol onto kaolinite (001) surface: A van der waals density functional study, Mater. Chem. Phys. 271, 124887 (2021)

84. L.R. Domingo, M. Aurell, P. Pérez, R. Contreras, Quantitative characterization of the global electrophilicity power of common diene/dienophile pairs in diels-alder reactions, Tetrahedron 58, 4417 (2002). DOI 10.1016/s0040-4020(02)00410-6 